\title{
USE OF SiMULATION SOFTWARE ENVIRONMENTS FOR THE Purpose of Production Optimization
}

\author{
Robert Ojstersek \& Borut Buchmeister
}
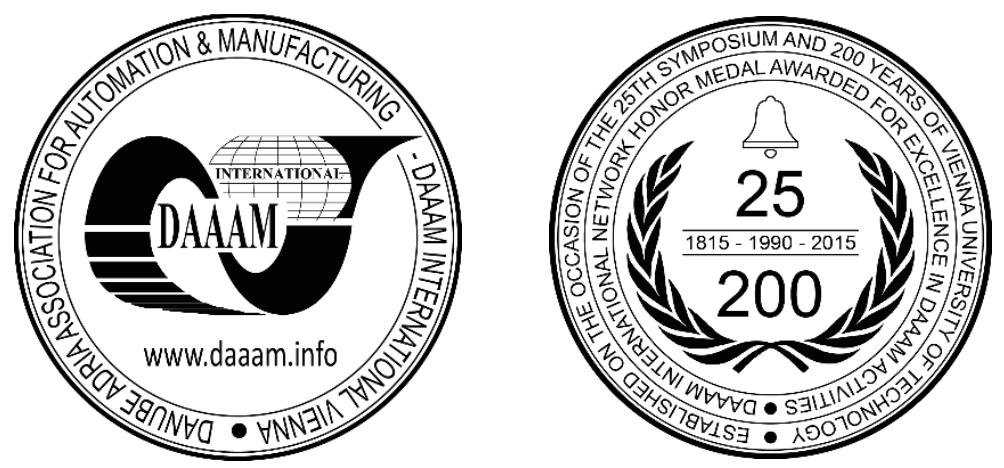

This Publication has to be referred as: Ojstersek, R[obert] \& Buchmeister, B[orut] (2017). Use of Simulation Software Environments for the Purpose of Production Optimization, Proceedings of the 28th DAAAM International Symposium, pp.0750-0758, B. Katalinic (Ed.), Published by DAAAM International, ISBN 978-3-902734-11-2, ISSN 1726-9679, Vienna, Austria

DOI: $10.2507 / 28$ th.daaam.proceedings.106

\begin{abstract}
This paper presents an introduction of two simulation environments for the purpose of optimizing production line. The time in which we are implementing the concept of Industry 4.0, a part of which is based on automated and robotic production systems, we want to pre-check financial and production efficiency of the proposed new updated concept of our existing production line. A comparison of two different programming environments for discrete systems simulation will be presented in this paper on the applied industrial example. Simulation model enables calculation of machine utilization, throughput time, number of finished products and minimum needed workers (MNW). If we want to justify the use of simulation environments for the purpose of optimizing production, we must firstly show the real world example as in presented paper. The result will justify the redesign of the existing production line and justify the use of simulation software tools for carrying out preliminary tests to create new more productive production line, which is designed on concept of Industry 4.0.
\end{abstract}

Keywords: Simulation; Simio; Autodesk Process Analysis $360^{\circ}$; Industry 4.0; Optimization

\section{Introduction}

Modern concepts of production are based on the introduction of automated production systems, this raises the questions; firstly, the financial justification of new investments in the existing manufacturing process, secondly, an appropriate allocation of labour force. Thirdly, if we had reached satisfying optimization of our production line which will be able to follow new trends and demands for a satisfactory period of time. Modern industry is turning to get the help from simulation software environments through which we can precisely define, optimize and simulate new manufacturing process. Throe the simulation results we can accurately determine production line specifications and parameters. In the final phase, operation of the system is simulated in a virtual environment to test real world parameters. The results of the simulations present the basic data for the comparative calculation of the eligibility of the existing system and proposed updates. With the introduction of the concept of Industry 4.0 [1] we must be also careful to a social aspect of labour. We must properly allocate the existing workforce. We must provide professional fulfilment in a new working area while we should not resort to unnecessary firing of the workers. 
The paper is organized as follows: in section 2 the literature review of simulation software is provided, in section 3 some basic approaches of simulations model are introduced. The two discrete system simulation environments Autodesk Process Analysis $360^{\circ}$ and Simio are presented in sections 4 and 5. Section 6 provides the details of designing, developing and implementing of simulation software's on applied example for the purpose of production optimization. Final section provides some conclusion about benefits and future advancements of simulation environments.

\section{Literature review}

Simulation environments are more and more powerful tools for precise execution of the new proposed concepts, models and production lines in field of scheduling and optimizing production environments. For this purpose, we can use a lot of different available simulation software packages. The problems are appearing when we want to combine our theoretical knowledge and mathematics concepts to new future proposed concepts in simulation environments. Many different authors have tried to integrate and compare multiple diverse simulation software and theoretical-mathematical models to get near optimal results for optimization of production environments.

Shirazi et al. [2] presented the use of simulation tools for solving flexible manufacturing systems, where the machines and tools are flexible; they can allocate the position and time of variables. Dehghanimohammadabadi et al. [3] present the concept of the intelligent simulation in which they integrate two different powerful simulation tools Simio and MatLab to create decision support system for optimization. We can see that many authors use simulation tools for: solving job shop scheduling problem (JSSP) with multiple-objects such as Ripon et al. [4] presents a use of mathematical simulation tool for solving crossover in JSSP. Wang et al. [5] present the simulation approach for process planning, operation determining and operational sequencing. Shundar et al. [6] represented the use of bee colony algorithm for solving JSSP in which they use some data analyser software to compare the mathematical data received from the simulation environment to real world data. The same problem is solved by the Wisittipanich and Kachitvichyanukil [7] which are using Microsoft Visual Studio and C\# programming language to solve this problem. Most of big factories around the world use simulation tools to simulate different approaches, methods and new concepts. Haider and Mirza [8] represent the manufacturing in Toyota production system, the methods of lean manufacturing and job shop production is presented on one-piece flow simulation. Another way to use the simulation environments is optimizing the layout and material flow analysis, Centobelli et al. [9] present the concept of digital factory which is founded on the simulation environments.

Many authors are still using priority rules for solving different non-deterministic polynominal-time hard (NP-hard) problems, but we can see that they use simulation environments instead of mathematical calculations. Zupan et al. [10] present the hybrid algorithm based on priority rules for simulation of workshop production, the results show the advantages of using simulation environments. We can also see that a lot of researchers use simulation environment to create and test new metaheuristic approaches such as Shuffled frog-leaping algorithm [11, 12], Intelligent water drops algorithm [13 - 15], Cloud-Entropy enhanced genetic algorithm [16] and so on [17]. Zgang et al. [18] present new hybrid multi-neighborhood based shuffled frog leaping algorithm with path relinking (RMN-SFLA-PR) for solving JSSP and MNW. RMN-SFLA-PR algorithm has a $100 \%$ success rate in the low-dimensional cases of the 4 benchmark (dj38) and converged to optimum ten times faster than individual algorithms in JSSP to solve MNW for the real world production line. They use MatLab environment for creating mathematical model and discrete system simulation environment Simio for testing the newly proposed algorithm on real world example. The mentioned things above show how useful are simulation environments and in how many diversified fields we can used them. But in some cases the usage of the simulation environments it is not so easy, programmes or researcher must have extended computational knowledge to create reliable and working simulation models. This paper presents the use of two different simulation environments, Autodesk Process Analysis $360^{\circ}$ and discrete system simulation tool Simio, to enable testing the productivity and the utilization of the new production line in comparison with the existing one.

\section{Simulation}

Simulation presents the transferred real system into computer programming language [19]. Designer build a computer model, which has the characteristics of the real world system. Created model represents a true picture of real industrial production line, to which we can add real world variables as mathematical variables or as a constant value in a specified period of time. In the simulation optimization of the production system, the world's leading companies use Autodesk software package Process Analysis $360^{\circ}$ and discrete system programming environment Simio. In the following chapters we will present this two simulation environments, their features and characteristics, which will be presented in the applied example of real world production line. In our simulation of production line we are focused on optimizing three main criteria; maximum makespan $C_{\max }$, defined by (3.1), the total flow time $F$ (3.2) and the utilisation of the machine centres $U R(3.3)[12]$.

$$
C_{\max }=\max \left\{C_{i}\right\}, 1 \leq i \leq n
$$

$C_{i}$ is the completion time of job $i, i=1, \ldots, n . n$ is number of jobs. 
$F=\sum\left(C_{i}-S_{i}\right), i=1, \ldots, n$

$C_{i}$ is the competition time and $S_{i}$ is the starting time of job $i, i=1, \ldots, n$.

$U R=\frac{\sum_{i=1}^{n} \sum_{j=1}^{m} p_{i j}}{m C_{\max }}, m$ is number of machines.

The processing time $p_{i j}$ represent the time job $j$ has to spend on machine $i$ [21].

\section{Autodesk Process Analisys 360}

Simulation of the production system in the programming environment Autodesk Process Analysis $360^{\circ}$ [22] enables as direct transfer of three-dimensional model from the software environment Autodesk Inventor to the software simulation environment Autodesk Process Analysis $360^{\circ}$. The advantage of the interconnectivity is represented in the entire software environment of Autodesk Factory Design Suite. With transferring the production system model in which are included all the data defined in the three-dimensional model created in Autodesk Inventor software environment, we transfer also mutual length, data of processing machines and the number of workers. In our case, we want to determinate the MNW. Real world example shows that the company already uses software from the manufacturer Autodesk environment, for example, AutoCAD, which is often used software environment for two-dimensional designs of the layout processing lines, and synchronization is possible between the two-dimensional model in AutoCAD and a three-dimensional model in Autodesk Inventor. Synchronization between the two-dimensional model in AutoCAD and the three-dimensional model is shown in Figure 1.
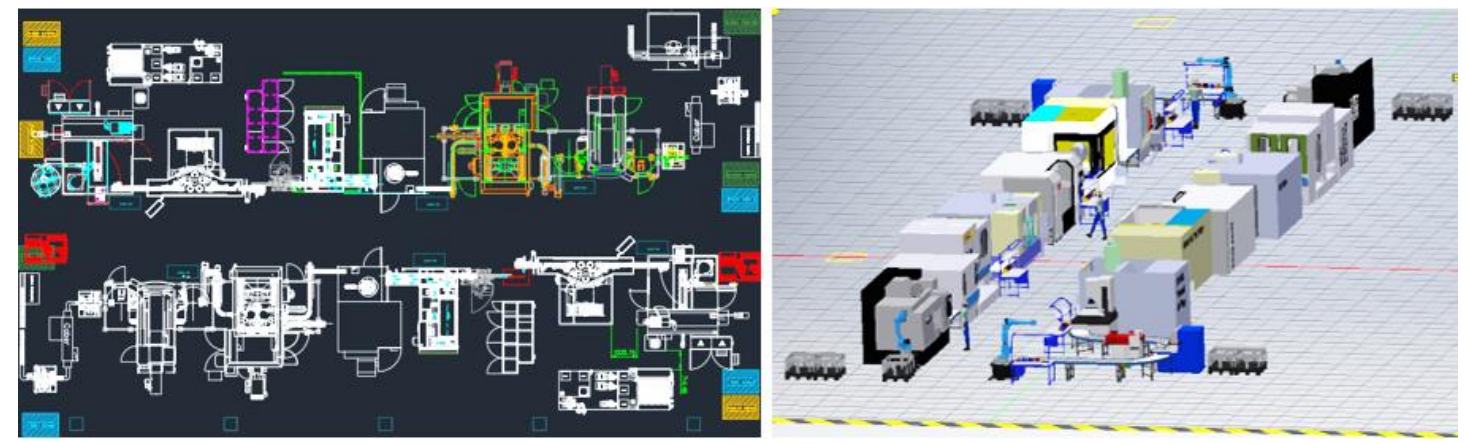

Fig. 1. A two-dimension model (left) and a three-dimensional model (right) of the production process

In the simulation environment Autodesk Process Analysis $360^{\circ}$ is required to enter real information about the vehicle speed, the speed of workers and conveyors, as well as time data: time to wait before processing, wait times on means of transport, downtime of production line and the duration of the simulation. The integrity of the software environment is reflected in the ease of use, versatility of existing information and interconnectivity of the entire software package Autodesk Factory Design Suite.

\section{Software environment Simio}

Simio is a simulation environment based on the use of intelligent objects [23]. Intelligent objects can be built by ourselves or we can use an existing object from the library. The use of existing objects is often the initial choice of the software users. Firstly, the object can be assigned as symbolic three-dimensional animation models and secondly, maybe even more important, is the possibility of transferring the real data captured from files of Microsoft Office Excel and SAP systems from production floor to the Simio software environment. For the mathematical assignment of characteristics and functions we used object-oriented programming languages $\mathrm{C}++, \mathrm{C}$ \#. For the simplified implementation of objectoriented programming language Simio provides already configured graphical programming framework. The pre-existing objects are divided into the following groups:

- Fixed object, representing objects that are stationary relative to the location.

- Agents, freely moving objects in three-dimensional space.

- Entity, subsystem of moving objects, often presented as a moving product.

- Link and Node, connect the movement of moving objects.

- Transporter, intended to define routes, positions, and the final destinations. 
Proper implementation of the objects is very important in order to obtain credible results in created simulation model. The model is well-defined with real world application characteristics and properties, which can be determined by the fixed values, or mathematical functions. The simulation model with real world characteristics and properties is presented in Figure 2. The advantage of the 3D graphical simulation model are simulation results, which can be used as a basis for a comparative simulation study between the existing and the proposed model of the new production line.

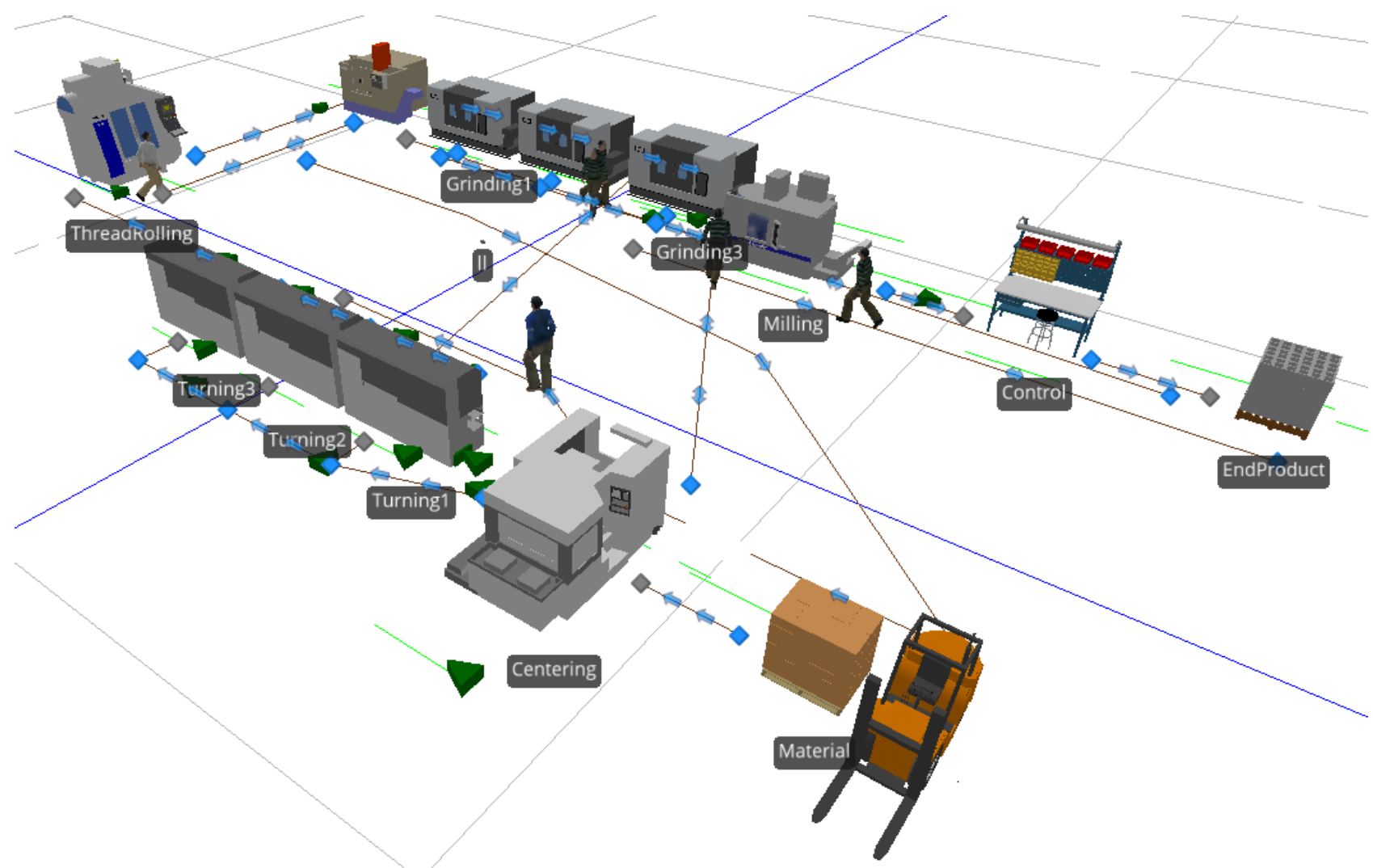

Fig. 2. Discrete system simulation in Simio

\section{Example of the use of simulation software environments for the purpose of production optimization}

Usage of simulation environment is very effective in the introducing of new concepts into an existing manufacturing process. Figure 3 shows the existing production line, which is not optimized. It consists of older types of machines with longer processing times and short mean time between failures $(M T B F)$. For the smooth functioning of the production line care six workers. As we know, the human factor reduces the reliability, robustness and productivity of the production line. Therefore, we propose new concepts of automated and robotized production lines (fundament on concept of Industry 4.0). The existing system consists of ten individual machining centers, including transportation systems, partly managed over the conveyor belt, partly manually transported using transport carts. Due to the influence of the human factor we can assume the loss of production time occurring during manual transporting and handling of the work pieces. Older unoptimized machining centre have longer production time per work piece. Ten machining centre perform operations listed below (in brackets are the operational times per work piece in seconds):

1. Centering $(20 \mathrm{~s})$,

2. External turning (67 s),

3. External turning (64 s),

4. External turning (66 s),

5. Rolling (18 s),

6. Hardening (24 s),

7. Grinding (65s),

8. Grinding (68 s),

9. Grinding (66s),

10. Groove milling (17 s).

It should be noted that the operations of external turning and grinding are carried on only one of the three machining centre. Transport of the work pieces from one machine centre to another is partly implemented via a conveyor belt, which travels at a speed of $0.1 \mathrm{~m} / \mathrm{s}$, and partly by carts pushed by workers which are working at the production line. Their speed 
of movement is between $70 \mathrm{~m} / \mathrm{min}$ and $75 \mathrm{~m} / \mathrm{min}$, depending on the weight of the transport carts. Delivery of semifinished products on the production line and the initial filling of the first machine center (centering machine) and also the removal of finished product from the production line is provided with a forklift. Speed of the forklift is $5 \mathrm{~km} / \mathrm{h}$ or 83.3 $\mathrm{m} / \mathrm{min}$ and it is electronically limited.

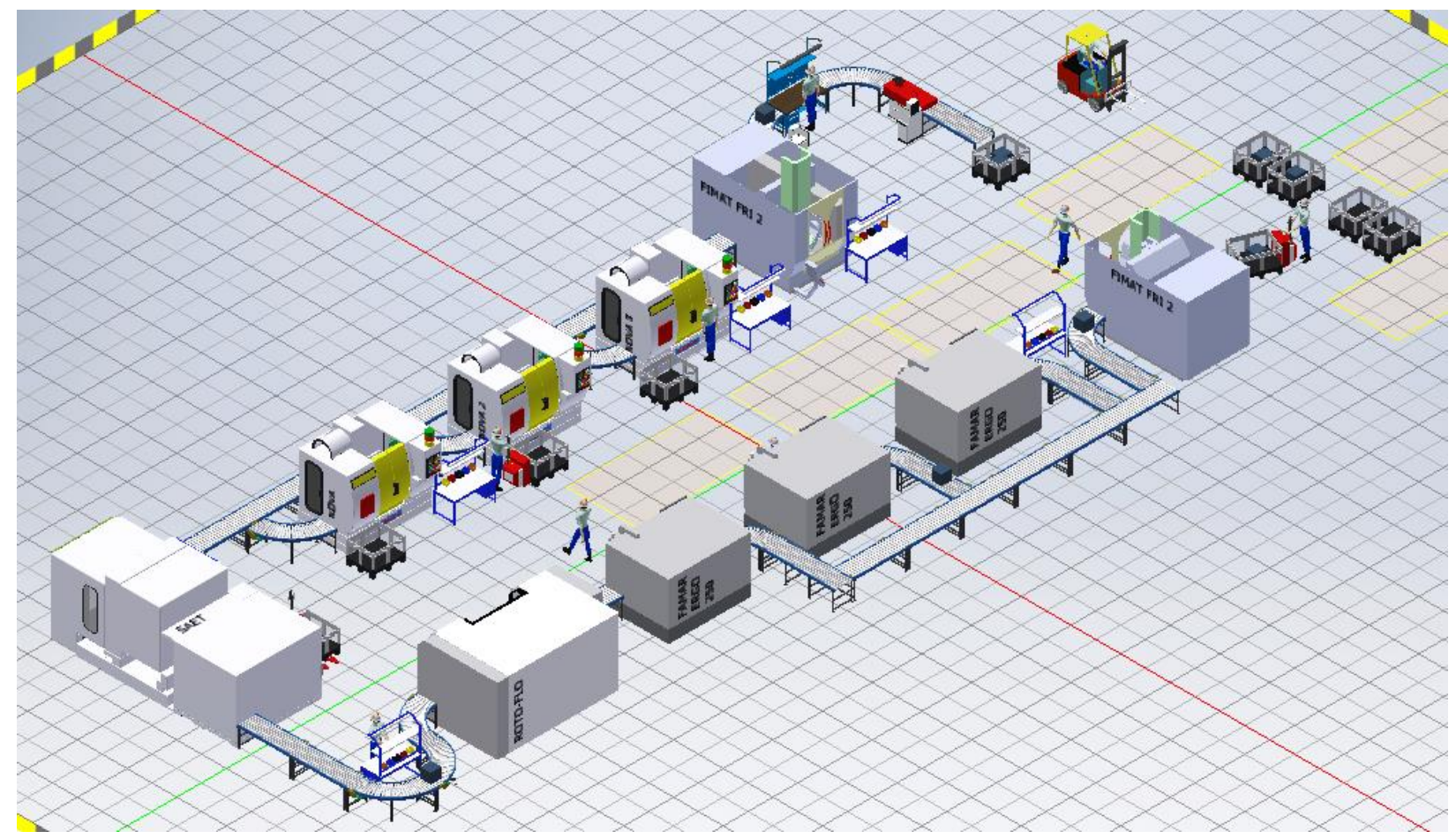

Fig. 3. A three-dimensional model of the existing production

The simulation results in Figure 4 show that the total utilization of the existing production line is $33.82 \%$. The simulation time is represented by one eight hour shift or 480 min. During 480 min shift a worker has one 30 min lunch break, two 10 min break and one 5 min break to get some rest between hard work. That's mean that the total production time of the simulation is $425 \mathrm{~min}$. In this time production line produced 440 finished products.

The simulation results are:

- Simulation time: 07:05:00 (h:m:s)

- Total Uptime of all machine centre: 1:02:21:18:203 (d:h:m:s:ms)

- Total Downtime of all machine centre: 03:57:11:000 (h:m:s:ms)

- $\quad$ Utilization: $33,82 \%$

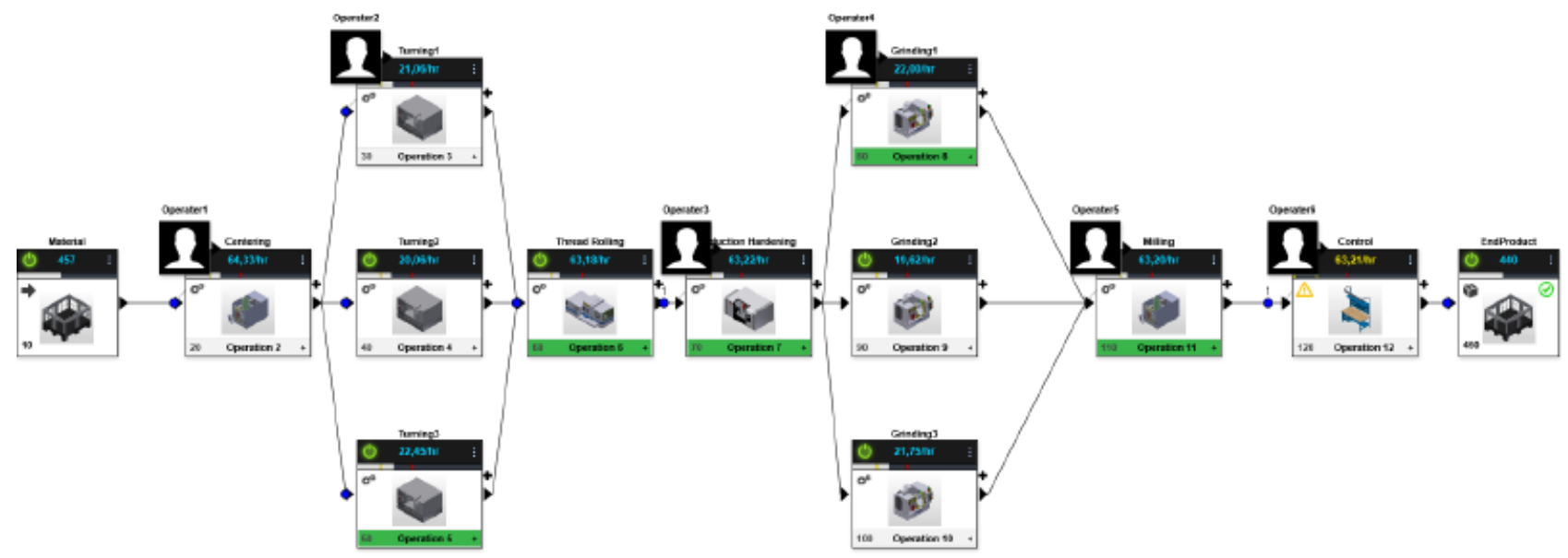

Fig. 4. Simulation model in Autodesk Process Analysis $360^{\circ}$

Figure 5 represent the graphical representation of the simulation results for the utilization of each individual machine centre, through which we can see single utilization, waiting times and potential bottlenecks in the production process. 


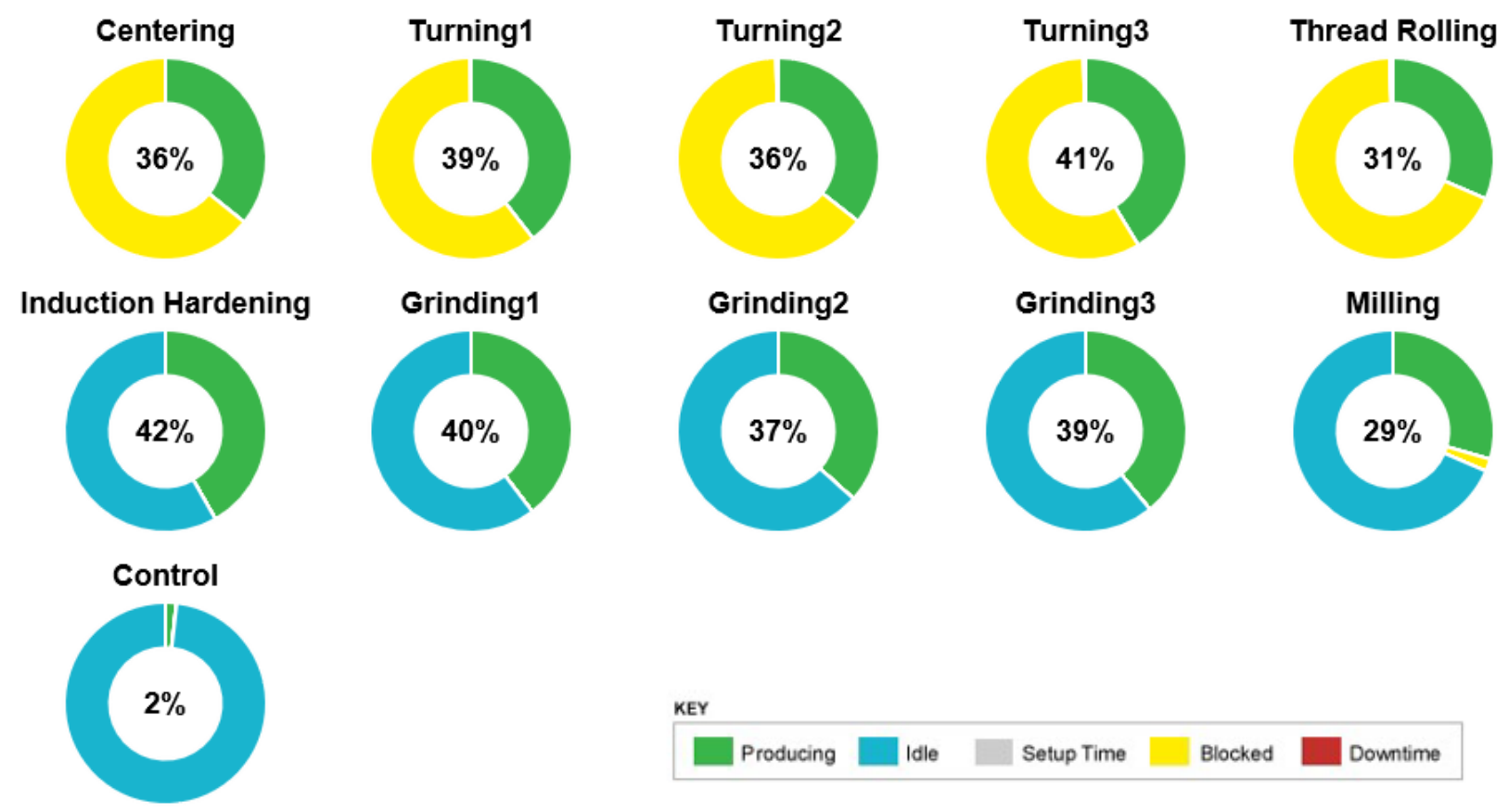

Fig. 5. Graphical presentation of the simulation results for the existing system

For better reliability of the simulation results we have also tested the simulation in simulation environment Simio. Simulation results in Simio shows that the total number of finished products is 448 parts within the simulation time period of $425 \mathrm{~min}$, which is the time of one work shift. Results shows that the amount of finished products in simulation environment is higher for 8 finished product compared to the simulation carried out in the software environment Autodesk Process Analysis $360^{\circ}$. Minimum difference between this two simulation environment can be attributed to real data entered into the simulation model and the impact of production downtime. We can also predict that the number of the completed products is related to the reliability factor of the workers. The simulation model has been tested several times, we tested with several applications and two durations:

- Short simulation time of one work shift, $425 \mathrm{~min}$.

- Long simulation time of the eighteen work shifts, $7650 \mathrm{~min}$.

From the obtained results we can see that the number of completed products differs just for two in positive or negative way, which demonstrate the reliability of the simulation. Then we started with creating of new proposed concept of production line. New production line has more productive machine centre with higher production rate lower MTBF and totally automated machining process. New production line consists of ten machine centers that perform operations listed below (in brackets are the operational times per work pieces in seconds):

1. Thread rolling (15 s),

2. Induction annealing (17 s),

3. Labelling (15 s),

4. Induction slackening (17 s),

5. Tooth controlling (17 s),

6 . Hard turning (24s),

7. Hard turning / milling (55 s),

8. Groove milling (28 s),

9. Groove controlling (17 s),

10. Product washing (17 s).

In new production line the transport of the product is carried out with conveyor belts, their speed is $0.1 \mathrm{~m} / \mathrm{s}$. Functioning of the production line is provided by three workers, who are responsible for the smooth operation of the machining centre and carrying out control checks on the work pieces. Delivery of semi-finished products on the production line is provided by a forklift. Speed of the forklift is $5 \mathrm{~km} / \mathrm{h}$ or $83.3 \mathrm{~m} / \mathrm{min}$ (electronically limited). Semi-finished products, which arrive in the production line from the external supplier are pre-treaded, also finished products are sent for corrosion protection, provided by external supplier. Feeding semi-finished products to the production line is carried out by using the robot to load the first machine centre (thread rolling). Also at the end of the production line a robot move finished products from the conveyor belt to the box. The implementation of robotic systems in the production process contributes to a more 
efficient, more reliable and faster production of the products. New concept of the production line is represented in Figure 6 , in which we can see new machine centre and the robots at the beginning and at the end of the production line.

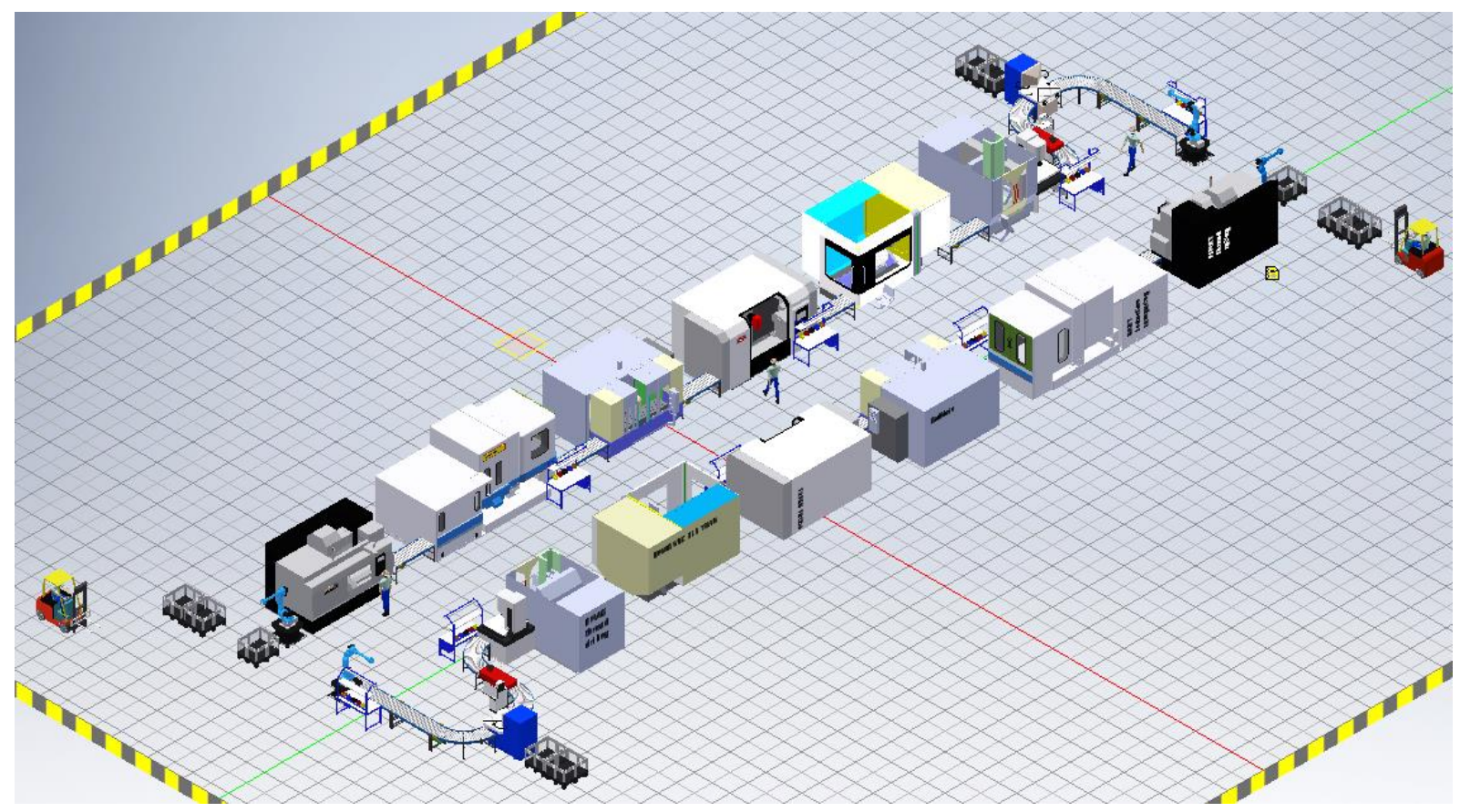

Fig. 6. Three-dimensional simulation model of the proposed new machining line

From the following Figure 7 can be seen an increase in the utilization of the production line from $33.82 \%$ (old production line) to $40.58 \%$ (new production line), utilization is increased by $6,76 \%$ or relatively by $20 \%$. It should be emphasized that the number of workers is decreased from the six workers at the old production line to three workers at the new production line. Smaller number of workers and higher productivity of the new machine centers are responsible for the smoother, faster, more repayable operations at the new production line. As we said the implementation of the automation and the robotisation in the new production line contributes to higher reliability, efficiency and robustness of the operating process.

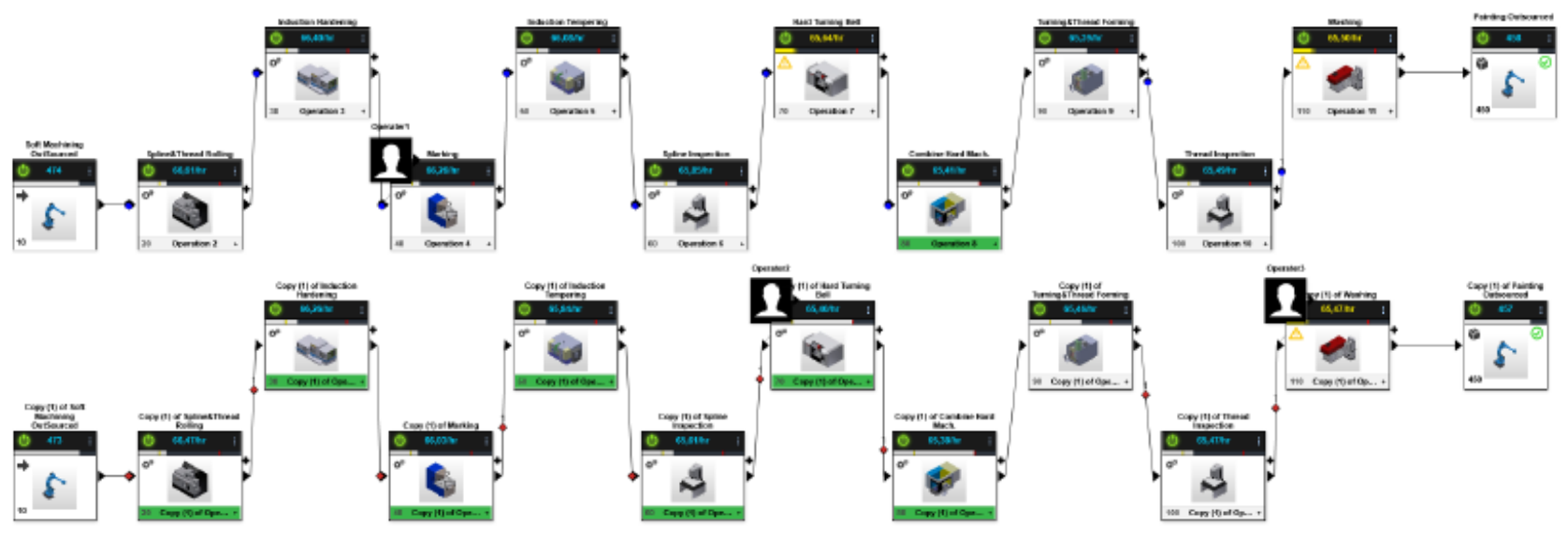

Fig. 7. Simulation model of the proposed concept

The results predict that the productivity of the new production line with implementation of a new concept will improve the finished number of products form 440 products to 457 products, manufactured on an individual branch of the newly proposed concept of the production line. Total number of finished product in the new line is 914 products, over a period of 425 minutes.

The simulation results are:

- Simulation time: 07:05:00 (h:m:s)

- Total Uptime of all machine centre: 2:09:29:09:228 (d:h:m:s:ms)

- Total Downtime of all machine centre: 08:37:42:150 (h:m:s:ms)

- $\quad$ Utilization: $40,58 \%$ 
From the graphical representation in Figure 8, we can see the increase of each machine centre utilization. The increase of the utilization can be attributed to the automation and robotisation of the production process.

\footnotetext{
Processor Utilization Charts

Utilization of processors relative to one another:
}

\section{Spline\& Thread Rolling Induction Hardening}

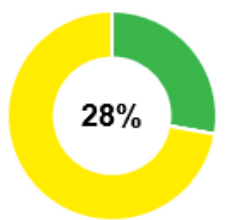

Hard Turning Bell

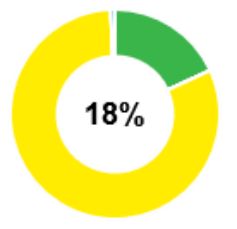

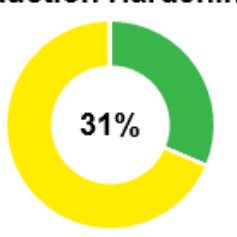

Combine Hard Mach. Turning\& Thread Forming
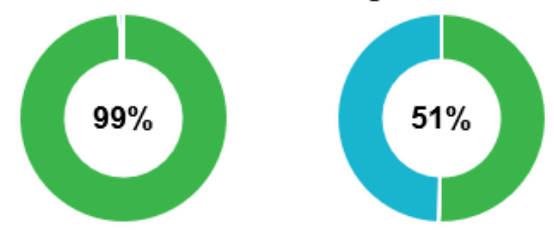

KEY

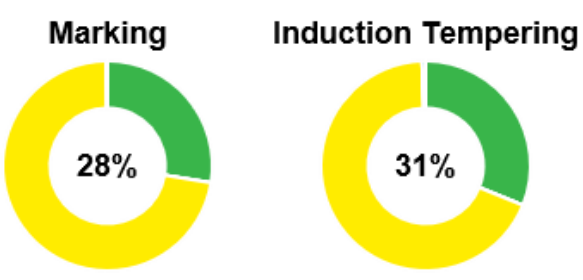

Thread Inspection

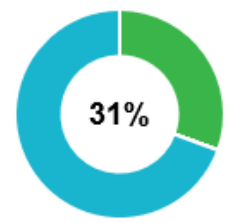

Spline Inspection
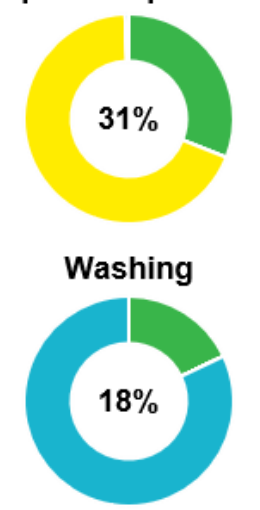

Fig. 8. Graphical display of occupancy of the machining line

Simulation study implemented in the programming environment Simio showed that the number of completed products of two central mirrored production lines (two branches) is higher than number of completed products of existing production line (Figure 9). From the obtained results we can see that the number of finished products differs just for four products in positive or negative way, which demonstrate the reliability of the simulation made in simulation programs Autodesk Process Analysis $360^{\circ}$ and Simio.

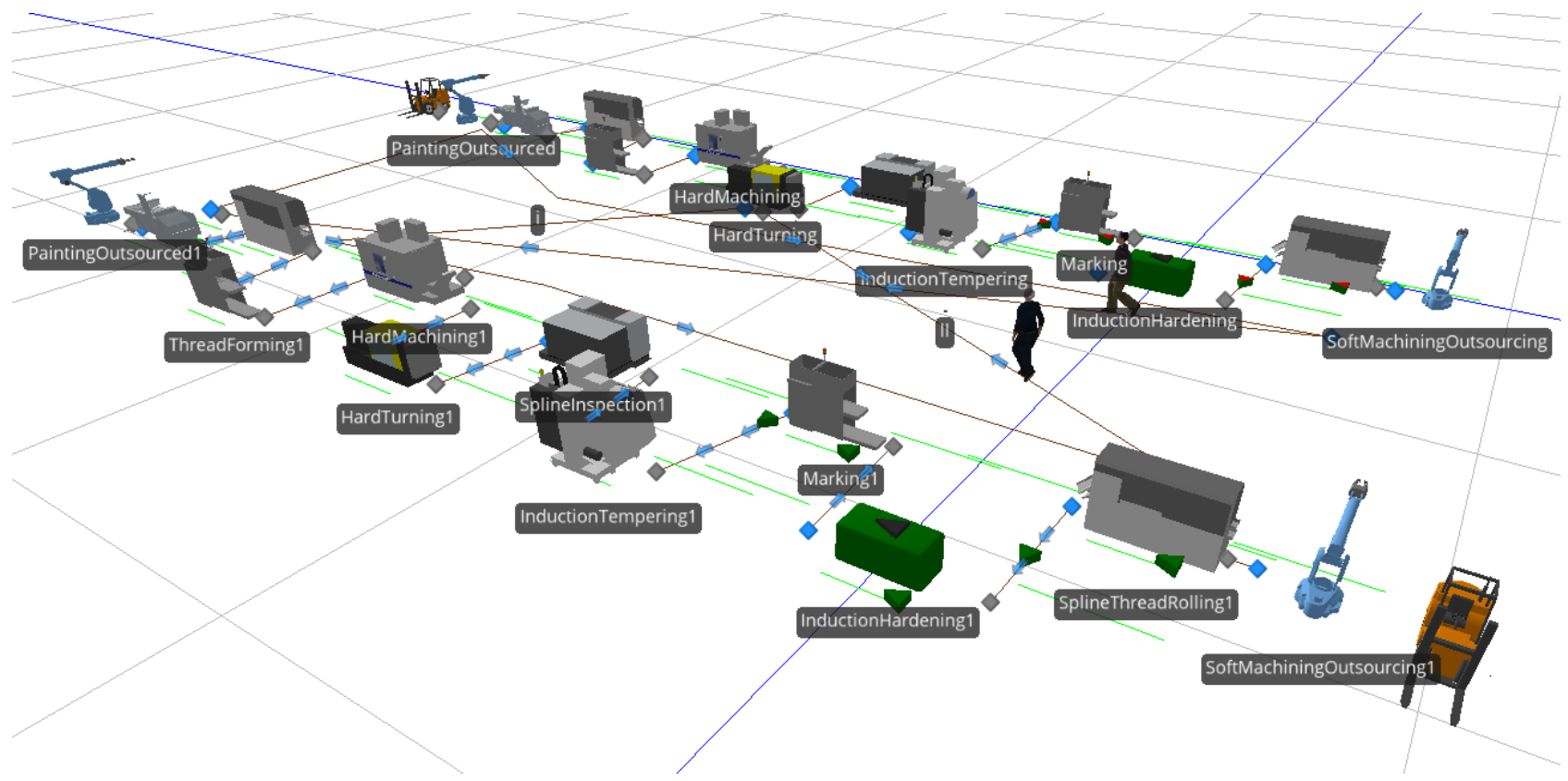

Fig. 9. Three-dimensional simulation model of the proposed new concept

\section{Conclusion}

The use of simulation packages, designed for simulation studies, indicates eligibility performance simulation, both for the purposes of comparing and of introducing the new concept of the production process. It provides a preliminary analysis of the financial justification of introducing new concepts into an existing manufacturing process. From the above, case it can be seen that the introduction of a new concept increases the productivity of the production line for $20 \%$, with a $10 \%$ raise the occupancy of machining centre. By reducing the number of workers (MNW), from six at the existing production line to two at the new proposed concept. Introduction of automated production systems increases the robustness of the 
system, the higher the reliability, the less the number of downtime, which leads to the financial justification of introducing automated systems in the production process. It proves the correctness of the simulation results matching final value of the two separate software environments. We can say that the introduction of simulation environments has a positive impact on the implementation of the concept of Industry 4.0 in the manufacturing process.

In the advancement, we will add some new metaheuristic methods for solving JSSP and MNW problem; we will combine MatLab code with discrete system simulation and metaheuristic methods. Newly proposed metaheuristic models in MatLab will be the fundament for creating near optimal multi-criteria optimization of JSSP. The focus will be on calculation of MNW at the production line.

\section{Acknowledgement}

The authors acknowledge the financial support from the Slovenian Research Agency (ARRS).

\section{References}

[1] Schwab, K. (2016). The Fourth Industrial Revolution, Word Economic Forum, Cologny/Geneva, Switzerland

[2] Sivakumar, A.I. (2001). Multiobjective dynamic scheduling using discrete event simulation. International Journal of Computer Integrated Manufacturing, Vol. 14, No. 2, pp. 154-167.

[3] Dehghanimohammadabadi, M. \& Keyser, T.K. (2017). Intelligent Simulation: Integration of SIMIO and MATLAB to deploy decision support systems to simualtion environmnet. Simulation Modelling Practice and Theory, Vol. 71, pp. 45-60.

[4] Ripon, K.S.N.; Siddique, N.H. \& Torresen, J. (2011). Improved precedence preservations crossover for multiobjective job shop scheduling problem, Evolving Systems, Vol. 2, No. 2, pp. 119-129.

[5] Wang, J.F.; Kang, W.L.; Zhao, J.L. \& Chu, K.Y. (2016). A simulation approach to the process planning problem using a modified particle swarm optimization. Advances in Production Engineering \& Management, Vol. 11, No. 2, pp. 77-92.

[6] Sundar, S.; Suganthan, P. N.; Jin, C. T.; Xiang, C. T. \& Soon, C. C. (2015). A hybride artificial bee colony algorithm for job-shop scheduling problem with no-wait constraint. Soft Computing, pp. 1-10.

[7] Wisittipanich, W. \& Kachitvichyanukul, V. (2013). An Efficient PSO Algorithm for Finding Pareto-Frontier in Multi-Objective Job Shop Scheduling Problems. Industrial Engineering \& Management Systems, Vol. 12, No. 2, pp. 151-160.

[8] Haider, A. \& Mirza, J. (2015). An implementation of lean scheduling in a job shop environment. Advances in Production Engineering \& Management, Vol. 10, No. 1, pp. 5-17.

[9] Centrobelli, P.; Cerchione, R.; Murino, T. \& Gallo, M. (2016). Layout and material flow optimization in digital factory. International Journal of Simulation Modelling, Vol. 15, No. 2, pp. 223-235.

[10] Zupan, H.; Herakovic, N.; Starbek, M. \& Kusar, J. (2016). Hybride algorithm based on priority rules for simulation of workshop production. International Journal of Simulation Modelling, Vol. 15, No. 1, pp. 29-41.

[11] Xu, Y.; Wang, L. \& Wang, S. (2013). An effective shuffled frog leaping algorithm for the flexible job shop scheduling problem. Proceedings of IEEE Computational Intelligence in Control and Automation, Published in 2013 IEEE Symposium on 16-19 April.

[12] Eusuff, M.; Lansey, K. \& Pasha, F. (2006). Shuffled forg-leaping algorithm: a memetic meta-heuristic for doscrete optimization. Engineering Optimization, Vol. 38, No. 2, pp. 129-154.

[13] Shah-Hosseini, H. (2008). Intelligent water drops algorithm: A new optimization method for solving the multiple knapsack problem. International Journal of Intelligent Computing and Cybernetics, Vol. 1, No. 2, pp.193-212.

[14] Shah-Hosseini, H. (2009). The intelligent water drops algorithm: a nature-inspired swarm-based optimization algorithm. International Journal of Bio-Inspired Computation, Vol. 1, No. 1/2, pp. 71-79.

[15] Shah-Hosseini, H. (2009). Evoltionary Computation: Optimization with the Nature-Inspired Intelligent Water Drops Algorithm, I-Tech, Vienna, Austria.

[16] Yongxiang, L.; Xifan, Y. \& Jifeng, Z. (2016). Multi-objective Optimization of Cloud Manufacturing Service Composition with Cloud-Entropy Enhanced Genetic Algorithm. Strojniški vestnik - Journal of Mechanical Engineering, Vol. 62, No. 10, pp. 577-590.

[17] Supsomboon, S. \& Vajasuvimon, A. (2016). Simulation Model for Job Shop Production Process Improvement in Machine Parts Manufacturing. International Journal of Simulation Modelling, Vol. 15, No. 4, pp. 611-622.

[18] Zhang, H.; Liu, S. \& Ojstersek, R. (2017). An effective use of hybride metaheuristic algorithm for job shop scheduling problem, International Journal of Simulation Modelling, in press

[19] Woolfson M. M.; Pert G. J. (1999). An Introduction to Computer Simulation. Oxford University Press, New York, USA.

[20] Buchmeister, B. (2013). Advanced job shop scheduling, DAAAM International, Vienna, Austria.

[21] Pinedo, M. L. (2005). Planning and Scheduling in Manufacturing and Services, Springer Science+Business Media, LLC, New York, USA.

[22] Strijker P. (2014). Hands-on: Factory Design Suite 2014, Autodesk Inc.

[23] Pegden C. D. \& Sturrock D.T. Intruduction to Simio. Winter Simulation Conference (2010), pp. 1-10 